\title{
Strength and Microfabric of Expansive Soil Improved with Rice Husk Ash and Lime
}

\author{
Jinrong Ma $\mathbb{D}^{1},{ }^{1}$ Yunhe Su $\mathbb{D}^{1},{ }^{1}$ Yuyi Liu $\mathbb{D}^{2},{ }^{2}$ and Xiangling Tao $\mathbb{D D}^{1,3,4}$ \\ ${ }^{1}$ State Key Laboratory for Geomechanics and Deep Underground Engineering, China University of Mining and Technology, \\ Xuzhou 221116, China \\ ${ }^{2}$ Anhui Huizhou Geology Security Institute Co., Ltd., Hefei 230000, China \\ ${ }^{3}$ Faculty of Architecture and Civil Engineering, Huaiyin Institute of Technology, Huai'an 223001, China \\ ${ }^{4}$ School of Transportation Engineering, Jiangsu Vocational Institute of Architectural Technology, Xuzhou 221116, China
}

Correspondence should be addressed to Xiangling Tao; chinatxl@126.com

Received 27 August 2019; Revised 1 October 2020; Accepted 20 October 2020; Published 31 October 2020

Academic Editor: Castorina S. Vieira

Copyright (C) 2020 Jinrong Ma et al. This is an open access article distributed under the Creative Commons Attribution License, which permits unrestricted use, distribution, and reproduction in any medium, provided the original work is properly cited.

Expansive soil has harmful effect on engineering. Rice husk ash (RHA) has high pozzolanic activity, so it can form new cementing material with lime or cement to solidify soil. In this paper, the tests of free expansion rate, water ratio limit, and optimum moisture content (OMC) are carried out; then, RHA and lime were added to artificial soil in different proportions of 5, 10, 15, and 20\% by weight, in which the ratio of RHA to lime is $80: 20$. The unconfined compressive strength (UCS) in different curing age is measured, and the improvement effect of RHA and lime to expansive soil can be obtained. Finally, the reason of improvement effect is explained by using the scanning electron microscope (SEM). The results of the study show that (1) for the best utilization effect, the optimum percentage of RHA is $12 \%$ and lime is $3 \%$; (2) the UCS is 2.6 times of the pure soil after curing of $14 \mathrm{~d}$ under the optimum percentage; (3) the curing age has a significant effect on strength; (4) the main reason for the strength increase of the modified soil is that the crystal produced by the pozzolanic activity fills the pores of the soil.

\section{Introduction}

Expansive soil is a special kind of clay, which is rich in hydrophilic minerals. At present, there are different methods to solve expansive soil. In recent years, the geopolymerization method is carried out to stabilize expansive soil. The geopolymerization occurs when an amorphous material rich in silica is mixed with soil in alkaline environment, such as bagasse ash and lime [1], fly ash and lime $[2,3]$, and volcanic ash and lime [4]. Among them, lime, as an additive, is the most commonly used to improve expansion soil. However, lime will change the $\mathrm{Ph}$ of soil which can affect the environment. Therefore, reducing the amount of lime is a very important subject in foundation engineering.

Rice husks account for about 20 percent of the total weight of rice. The quantity of rice husk is large, but there is no reasonable way to utilize it on a large scale. The biomass power generation technology has alleviated the problem to some extent, but the enterprises have no idea to deal with the RHA produced after the power generation. Cook [5] believes that RHA, which is rich in silicon, can be used as pozzolanic material to produce geopolymer to improve the performance of expansive soil. Therefore, some scholars have added RHA into the expansive soil to study its engineering properties.

Aziz [6] found that the RHA has a great influence on the high plastic soil. It can decrease the swelling property and increase the strength. Singh [7] indicated that when the content of RHA in the soil samples is $10 \%$, the CBR and unsoaked CBR reach their peak and the expansive force is the lowest. The engineering properties of soil mixed with RHA and its application prospect on roadbed were studied by Muntohar [8], Rao and Ganja [9], and Oviya [10]. In their studies, RHA played an important role in soil improvement. Kumar [11] found that when the lime content is 
more than $3 \%$, there is no substantial effect on the strength increase. Agus Muntohar's research studies [12] showed that more than $10 \%$ lime content would cause plastic failure of soil during compression. Sabat [13] found that the curing period should be more than 7 days (d). Liu et al. [14] presented a cementitious material combined with RHA and lime to stabilize expansive soil and studied the deformation and strength properties of stabilized soil.

Previous studies mainly focused on the physical and mechanical properties of the soil after solidification, lacking of the observation, and analysis of the microfabric during the solidification process. In this paper, the UCS experiment and the observation of the expansive soil microfabric by SEM are carried out. The changes of the mechanical properties and the microstructure characteristics are observed and analyzed during different curing time.

\section{Preparation of Sample and Description of Tests}

2.1. Basic Properties of the Test Materials. The expansive soil used in this paper was taken from the construction site of Wanja-Yichun expressway in Yichun city, China, and the depth of the soil sample is 4-6 meters. The free expansion ratio, limit moisture content, and compaction experiment of the expansive soil were carried out under the Chinese standard-GB/T 50123-1999.

(1) The free expansion rate of expansive soil used in this experiment is $132 \%$, which belongs to strong expansive soil

(2) The plastic limit, liquid limit, and plasticity index of soil samples are $36.9,77.6$, and 40.7 , respectively

(3) The optimum water content of the soil sample is $28 \%$ and the maximum dry density is $1.37 \mathrm{~g} / \mathrm{cm}^{3}$

Undamaged RHA is taken from a biomass power generation company in Huaian, China. The RHA and lime used in the experiment are shown in Figures 1 and 2 . The particle size of RHA, lime, and soil is measured by laser particle size analyzer. The data of Figure 3 are obtained. The average specific surface area of the RHA is $5910 \mathrm{~cm}^{2} / \mathrm{g}$ and the particle size $D_{50}$ is $7.449 \mathrm{um}$; the average specific surface area of the lime is $13880 \mathrm{~cm}^{2} / \mathrm{g}$ and its particle size $D_{50}$ is $3.110 \mathrm{um}$. The $D_{50}$ of soil is $20.005 \mathrm{um}$. The grain size of the RHA and the lime is very small, which can fill in the soil voids to increase the compactness.

The chemical composition of raw materials is shown in Table 1. As can be seen from the table, the main components of soil are $\mathrm{SiO}_{2}, \mathrm{Al}_{2} \mathrm{O}_{3}$, and $\mathrm{Fe}_{2} \mathrm{O}_{3}$, and the main component of lime is $\mathrm{CaO}$. RHA is rich in $\mathrm{SiO}_{2}$.

2.2. Design of Experiment Methods. It is necessary to determine the optimum ratio of RHA and lime. The RHA and lime with different mixing ratios were mixed into standard sand to make samples. After curing for $7 \mathrm{~d}, 14 \mathrm{~d}$, and $28 \mathrm{~d}$, the compressive strength and breaking strength of this samples were tested. It was found that when the ratio of RHA and lime was $80: 20$, the compressive strength and breaking strength of the samples were the highest at different curing ages. So this ratio is adopted to make the soil samples.

Most scholars control the content of RHA within 0-20\%, so in this paper, the amount of ash added accounts for $0 \%$, $5 \%, 10 \%, 15 \%$, and $20 \%$ of the dry soil weight, respectively.

In order to ensure the universality of the mesoscopic analysis in this paper, the UCS of soil samples are obtained under different curing ages. By comparing with the results of other scholars' tests, the generality of the materials used in this paper is verified and illustrated. Then their microfabric is observed and analyzed, and the reasons of the improvement are obtained.

\section{Analysis of UCS of Modified Expansive Soil}

The results of compaction experiment showed that the OMC of expansive soil is $28 \%$. However, the OMC of the mixture will be greater than $28 \%$ because of the RHA's high hydroscopicity. In this test, the moisture content of mixtures is 1 times (28\%), 1.2 times (34\%) and 1.4 times (40\%) than the OMC of pure soil. After curing to the corresponding age in the standard maintenance room, the tests of UCS were carried out under the Chinese standard-GB/T 50123-1999. The data are shown in Figures 4-6.

Compared with the pure soil at $28 \%$ moisture content, the UCS of the mixture at $34 \%$ moisture content and $15 \%$ ash content are 2.1 times, 2.6 times, and 2.8 times of the pure soil after curing of $7 \mathrm{~d}, 14 \mathrm{~d}$, and $28 \mathrm{~d}$, respectively. Analogously, the UCS of $20 \%$ ash-filled soil at the corresponding curing age is 2.4 times, 3 times, and 3.2 times of pure soil, respectively. It can be obtained that soil samples form a certain strength after $7 \mathrm{~d}$ of curing. When the soil is cured for $14 \mathrm{~d}$, the strength increase is basically completed, and the strength increases slowly during the subsequent curing. The results agree with Akshaya Kumar Sabat [13] that the curing period of RHA-lime improved soil should be longer than $7 \mathrm{~d}$.

The UCS of the soil sample increases with the increase of the ash content and curing age when the ash ratio is less than $20 \%$. Through the compaction experiment, it can be obtained that the UCS of the sample is the maximum when the moisture content of the sample is 1.2 times the OMC of pure soil. Therefore, the OMC of mixtures samples is 1.2 times that of pure soil. Under the OMC, the UCS of samples with $15 \%$ ash content is 1.74 times that of the samples with $10 \%$ ash content, and UCS of the tests with $20 \%$ ash content is 1.13 times that of the samples with $15 \%$ ash content. Therefore, the improvement effect of soil with $15 \%$ ash content is obviously better than that of samples with $10 \%$ ash content, but the improvement effect of samples with $20 \%$ ash content is not obvious compared with that of samples with $15 \%$ ash content. Therefore, $15 \%$ ash content is chosen as the optimum mixing ratio considering the engineering cost. Because RHA and lime are mixed into soil according to the proportion of $80: 20$, when the amount of ash is $15 \%$, the lime content is $3 \%$ of the dry weight of the soil and the RHA is $12 \%$.

The optimum lime content is consistent with that of Kumar [11] (3\%) and Muntohar [12] (no more than 6\%). The results of Sabat [15] study showed that $10 \%$ of RHA and $4 \%$ 


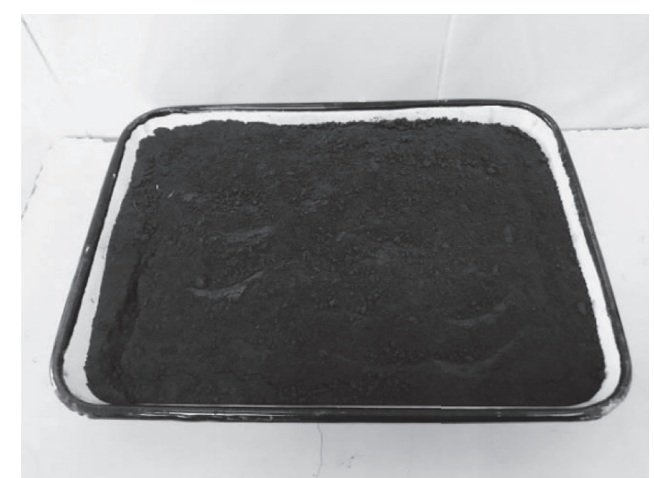

Figure 1: The RHA used in this study.

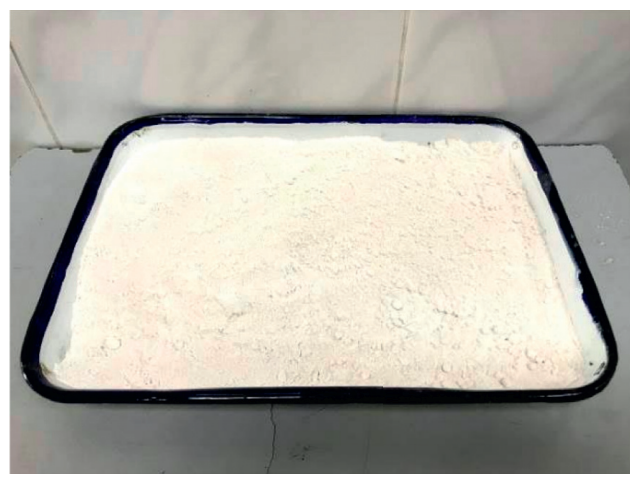

Figure 2: The lime used in this study.

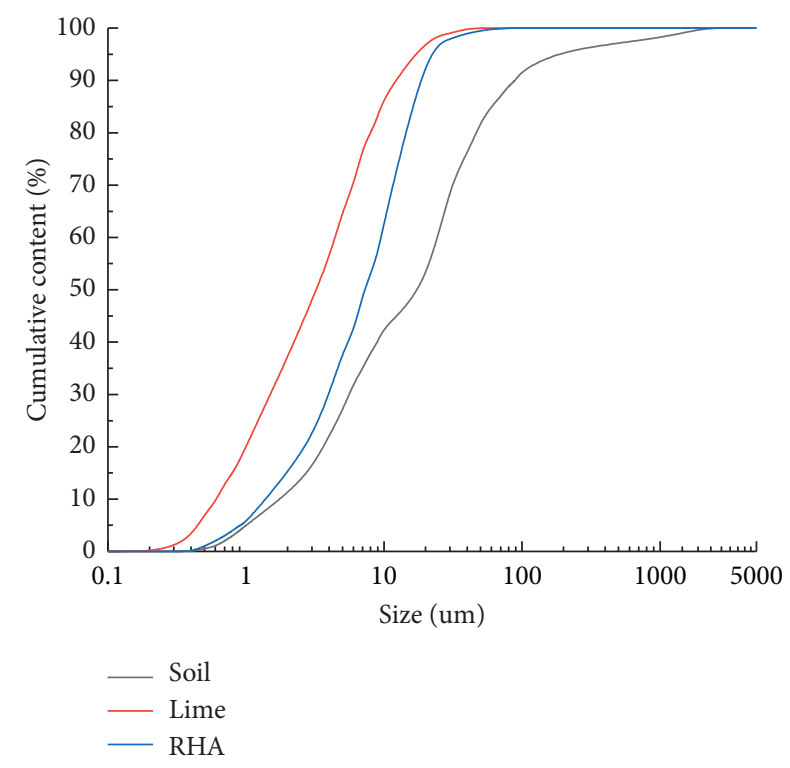

FIGURE 3: The grain composition of raw materials.

of lime content were the best and Aziz [6] considered 16\% RHA as the optimal ratio. The ratio obtained in this chapter was consistent with those results. Therefore, the optimum mixture ratio of RHA and lime is $12 \%$ and $3 \%$ of dry soil weight, re-
TABLe 1: Chemical compositions of raw materials.

\begin{tabular}{lccc}
\hline & \multicolumn{3}{c}{ Chemical composition (\%) } \\
& Soil & RHA & Lime \\
\hline $\mathrm{SiO}_{2}$ & 58.7 & 72.3 & 0.1 \\
$\mathrm{CaO}$ & 5.8 & 1.5 & 92.3 \\
$\mathrm{Al}_{2} \mathrm{O}_{3}$ & 18.4 & 4.4 & 0.6 \\
$\mathrm{Fe}_{2} \mathrm{O}_{3}$ & 7.1 & 1.2 & 0.5 \\
$\mathrm{~K}_{2} \mathrm{O}$ & 3.5 & 3.5 & 0 \\
$\mathrm{MgO}$ & 2.0 & 1.0 & 0 \\
$\mathrm{Na}_{2} \mathrm{O}$ & 1.1 & 0.8 & 0.3 \\
\hline
\end{tabular}
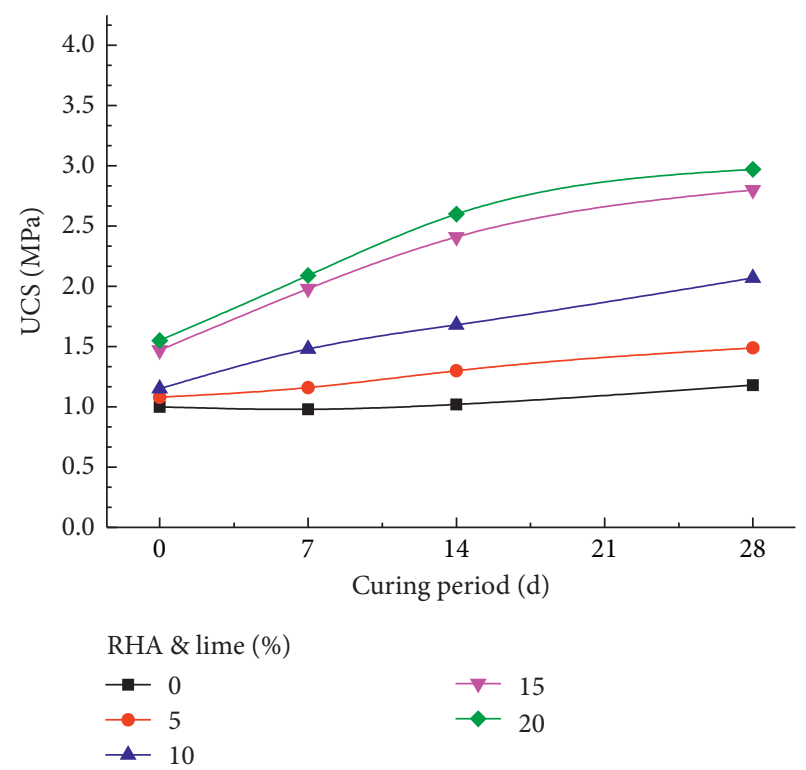

FIGURE 4: The UCS of soil with $28 \%$ water content.

spectively, in this study and the conclusion of next chapter about the microanalysis of soil has universal significance.

\section{Microfabric Analysis of Modified Expansive Soil}

The mechanical and engineering properties of expansive soil mixed with RHA and lime have been studied by many researches, but there is a lack of analysis of microfabric change of soil samples during the curing period. In order to analyze the improvement mechanism of RHA and lime further, the microfabric of expansive soil was studied by SEM.

The mixture (RHA and lime in the proportion of $80: 20$, ash content at $15 \%$ of dry weight of soil) at different ages ( $7 \mathrm{~d}$, $14 \mathrm{~d}$, and $28 \mathrm{~d}$ ) as observed by SEM, and the pore structure and microscopic characteristics were obtained. The structure and development trend of hydration products of soil samples during curing and hardening are analyzed.

Because there were too many soil samples of different curing age and different amount of ash, only 15\% SEM images are selected for comparative analysis.

It can be seen from Figure 7 that there is no bond between sample particles without curing, and the particles are 


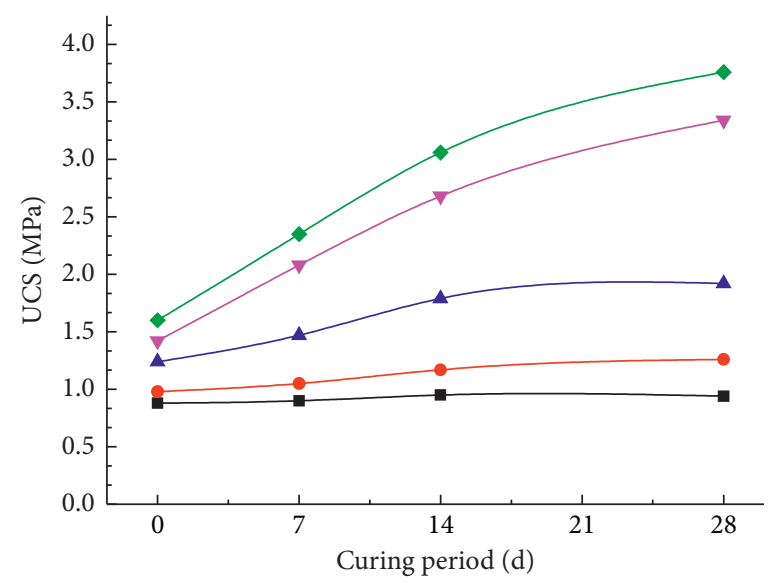

RHA \& lime (\%)

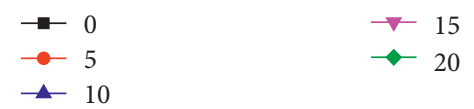

FIgURE 5: The UCS of soil with $34 \%$ water content.

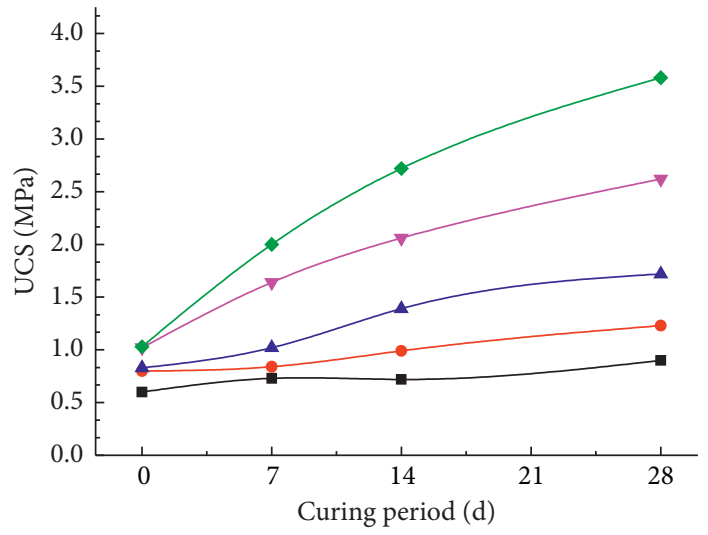

RHA \& lime (\%)

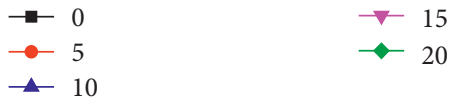

Figure 6: The UCS of soil with $40 \%$ water content.

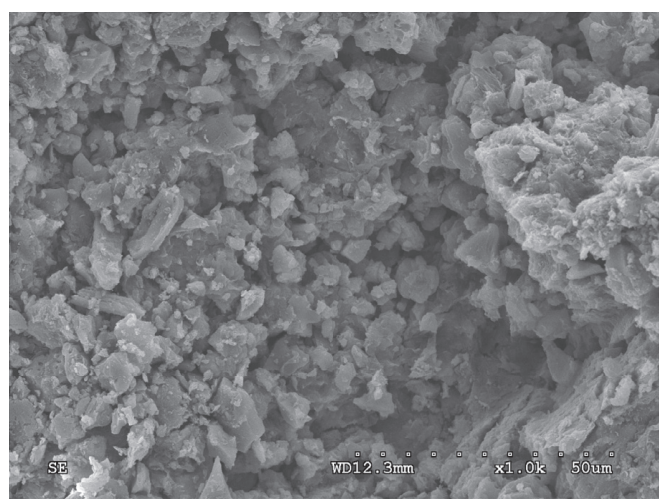

FIgURE 7: The soil of curing $0 \mathrm{~d}$ and being magnified 1000 times. 


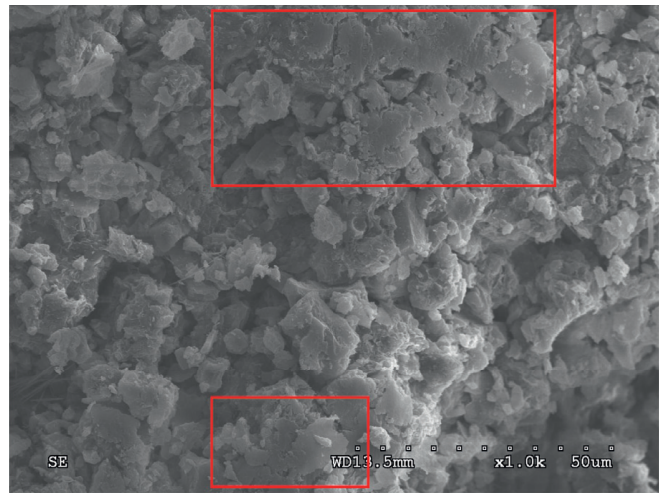

Figure 8: The soil of curing $7 \mathrm{~d}$ and being magnified 1000 times.

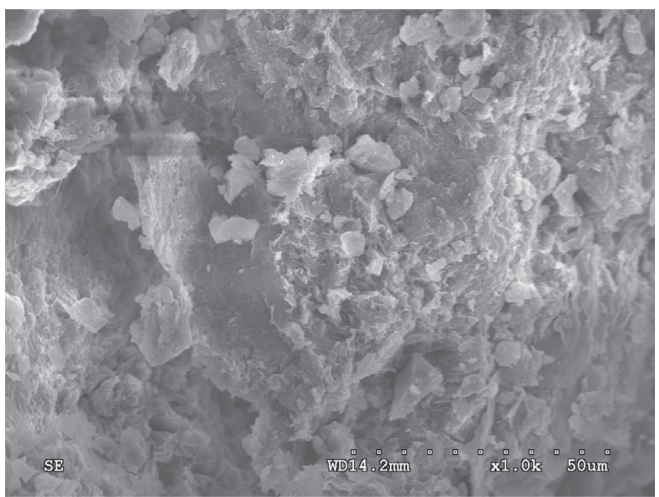

Figure 9: The soil of curing $14 \mathrm{~d}$ and being magnified 1000 times.

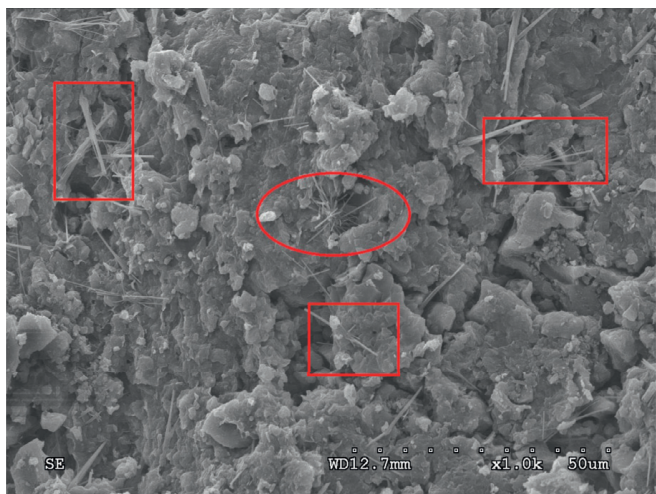

Figure 10: The soil of curing $28 \mathrm{~d}$ and being magnified 1000 times.

spaced loosely. As can be seen from Figure 8, the boundary between particles has begun to blur after $7 \mathrm{~d}$ of soil maintenance, and, in the square frame of Figure 8 , soil particles have been bonded as a whole. In Figure 9, most of the soil samples are bonded as a whole after $14 \mathrm{~d}$ of maintenance, with only a few loose particles existing. From Figure 10, after $28 \mathrm{~d}$ of curing, the vast majority of the soil is bonded into blocks and needle-like objects can be clearly seen in the square. The cluster and flocculation materials formed by the reaction of RHA, lime, and soil were enlarged to 10000 times in the elliptical frame of the image, and the morphology of flocculating material could be observed in detail in Figure 11.

The pore between particles and the morphology of cluster materials can be seen at 10000 times after curing.

As shown in Figures 12-15, when magnified by 10000 times, it is clear that there is no connection between the particles at $0 \mathrm{~d}$; after $7 \mathrm{~d}$, there are two needles between particles; at $14 \mathrm{~d}$ of curing, cluster of substances can be seen and it continues to evolve into flocculating substances after $28 \mathrm{~d}$. As shown in Figure 16, because the RHA has rich pore structure 


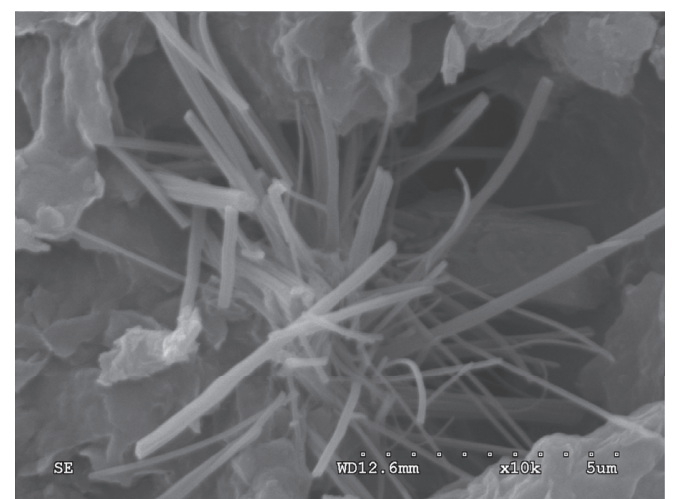

Figure 11: The soil of curing $28 \mathrm{~d}$ and being magnified 10000 times (1).

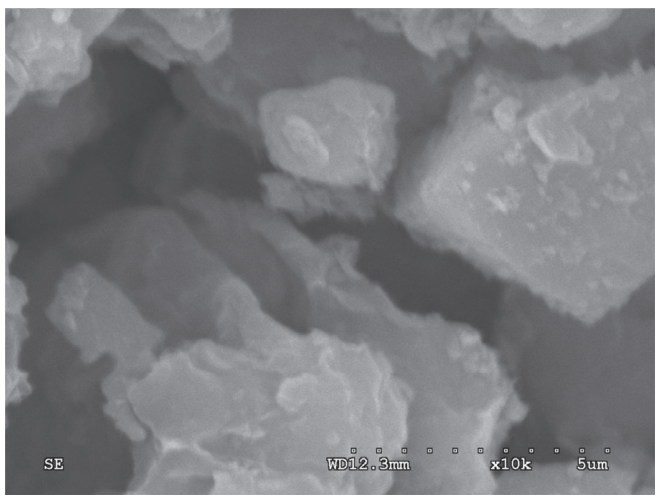

Figure 12: The soil of curing $0 \mathrm{~d}$ and being magnified 10000 times.

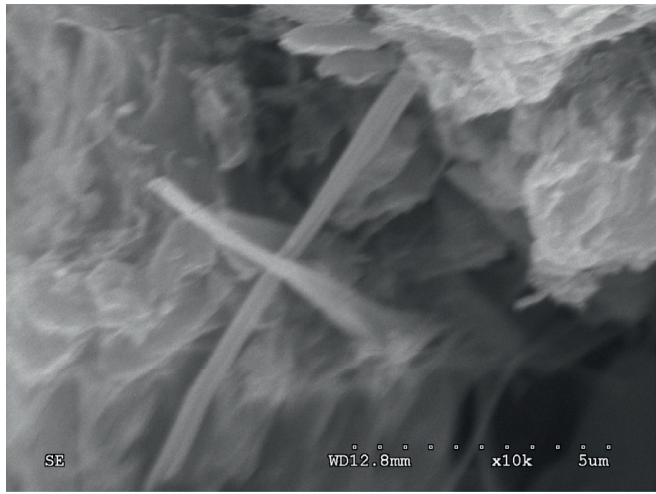

Figure 13: The soil of curing $7 \mathrm{~d}$ and being magnified 10000 times.

and is rich in active silica, there will be a pozzolanic reaction in the soil mixed with RHA and lime, which will produce a coagulant to fill the soil pores to increase the strength.

Ali [16] studied the soil modified by RHA and lime. The results showed that calcium silicate octahydrate, calcium aluminate trihydrate, and calcium silicate monohydrate were gradually formed in the soil. But generally speaking, the content of silica in RHA is more than $70 \%$, so the author thinks that the aluminum element in the conclusion of Ali mainly comes from expansive soil, including montmorillonite, illite, and kaolin. Therefore, the direct reaction caused by the addition of RHA and lime is the formation of calcium silicate hydrate, which gradually precipitates into crystals during the curing process, resulting in clusters and flocculation structure, as shown in Figures 14 and 15.

Since fly ash also has pozzolanic activity, the mechanism of improving soil by fly ash has been studied to some extent. It is considered that the main reasons for the improvement 


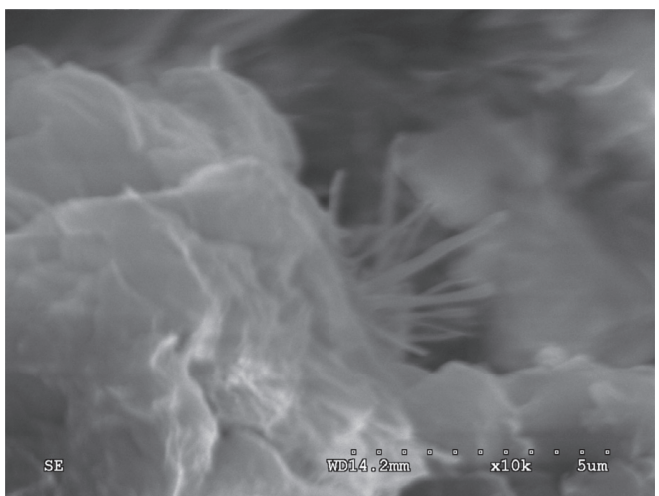

FIgURE 14: The soil of curing $14 \mathrm{~d}$ and being magnified 10000 times.

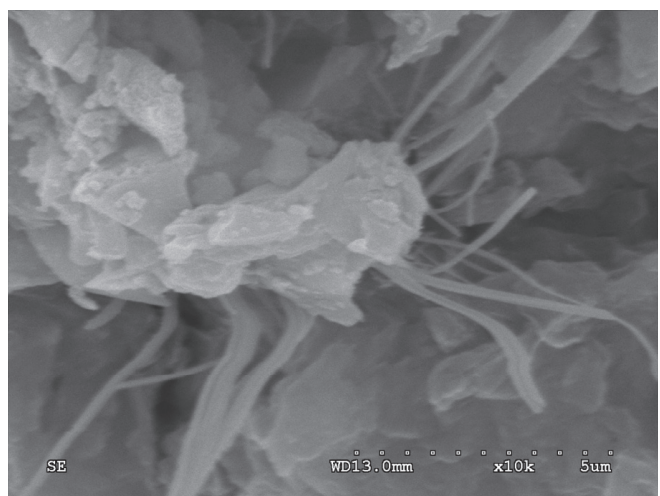

FIGURE 15: The soil of curing $28 \mathrm{~d}$ and being magnified 10000 times (2).

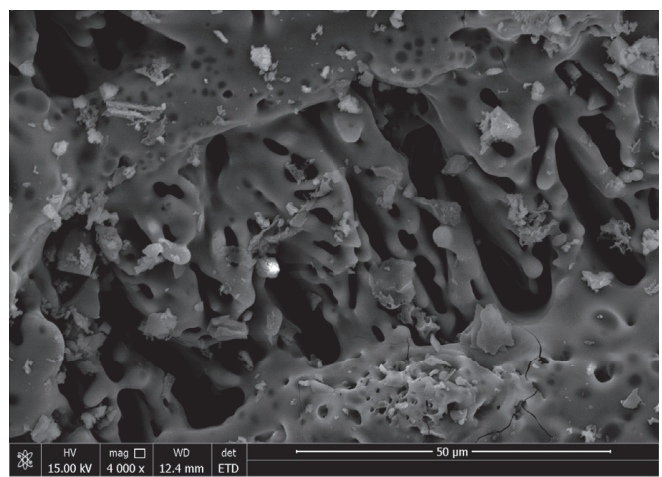

Figure 16: Raw rice husk ash of being magnified 4000 times.

of soil by lime and fly ash include the following four aspects: ion exchange, carbonation, pozzolanic action, and crystallization. Through the understanding of the composition of RHA and the observation by SEM, it can be concluded that the RHA and lime will react with the soil and the product will crystallize with time. Because the RHA is an ideal pozzolanic material which can react with lime to cause geopolymerization, the active $\mathrm{SiO}_{2}$ in RHA dissolved by $\mathrm{Ca}(\mathrm{OH})_{2}$ in lime can generate the $\mathrm{CaSiO}_{3} \cdot \mathrm{nH}_{2} \mathrm{O}$, which can fill the voids in soil. What is more, the $\mathrm{Al}_{2} \mathrm{O}_{3}$ in soil also can react with lime and $\mathrm{CaSiO}_{3} \cdot \mathrm{nH}_{2} \mathrm{O}$. As a result, the ettringite is formed which can be seen in Figures 12 and 16 clearly. Besides, the addition of small particle size, such as RHA and 
lime, will lead to agglomeration of soil. Under these effects, the porosity of soil will decrease for the long term.

\section{Conclusion}

The following conclusions can be drawn:

(1) Because of the high hydroscopicity of RHA, the UCS reaches its peak when the OMC of mixture is 1.2 times than pure soil.

(2) Considering the strength and the engineering cost, $15 \%$ ash content is the optimum mixing ratio, in which the ratio of RHA to lime is $80: 20$.

(3) The curing age has a significant effect on strength. The soil sample has a certain strength at $7 \mathrm{~d}$ of curing, and the strength increase is basically completed after $14 \mathrm{~d}$.

(4) The acicular fibers produced in the pores of the modified expansive soils increased gradually during the curing period and finally formed flocculating structures. These fibers are formed by active silica in RHA and calcium hydroxide in lime. The RHA has high pozzolanic activity and this progress is geopolymerization.

(5) The main reason for the strength increase of the modified soil is that the crystal fills the pores of the soil so that the soil particles are connected together. On the other hand, the addition of RHA and lime has a certain filling effect because of their smaller particle size which plays a certain role in the solidification of soil.

\section{Data Availability}

The numerical data used to support the findings of this study are included within the article. All the lab test data and calculation results data used to support the findings of this study are also available.

\section{Conflicts of Interest}

The authors declare that they have no conflicts of interest.

\section{References}

[1] B. A. Mir, "Some studies on the effect of fly ash and lime on physical and mechanical properties of expansive clay," International Journal of Civil Engineering, vol. 13, no. 3, pp. 203-212, 2015.

[2] T. P. Mashifana, F. N. Okonta, and F. Ntuli, "Geotechnical properties and microstructure of lime-fly ash-phosphogypsum-stabilized soil," Advances in Civil Engineering, vol. 2018, Article ID 3640868, 2018.

[3] J. James and P. K. Pandian, "Bagasse ash as an auxiliary additive to lime stabilization of an expansive soil: strength and microstructural investigation," Advances in Civil Engineering, vol. 2018, Article ID 9658639, 2018.

[4] Y. Cheng, S. Wang, J. Li, X. Huang, C. Li, and J. Wu, "Engineering and mineralogical properties of stabilized expansive soil compositing lime and natural pozzolans," Construction and Building Materials, vol. 187, pp. 1031-1038, 2018.

[5] D. J. Cook, "Rice husk ash as a pozzolanic material, in Proceedings of a Conference on New Horizons in Construction Materials," Lehigh University, Bethlehem, PA, USA, 1976.

[6] M. Aziz, M. Saleem, and M. Irfan, "Engineering behavior of expansive soils treated with rice husk ash," Geomechanics and Engineering, vol. 8, no. 2, pp. 173-186, 2015.

[7] V. K. Singh, "Experimental study of stabilization on natural soil subgrade using rice husk ash," International Journal for Scientific Research \& Development, vol. 3, no. 11, pp. 14-18, 2016.

[8] A. S. Muntohar, "Engineering behaviour rice husk ash blended soil and it's potential as road base construction," Conference of the Australian Road Research Board, vol. 21, pp. 1295-1301, 2003.

[9] D. K. Rao and V. Ganja, "A laboratory study of cyclic plate load test on lime and rice husk ash treated marine clay subgrade flexible pavements," International Journal of Modern Engineering Research, vol. 2, no. 5, pp. 4465-4469, 2012.

[10] R. Oviya, "An experimental investigation on stabilizing the soil using rice husk ash with lime as admixture," International Journal of Informative \& Futuristic Research, vol. 3, pp. 3511-3519, 2016.

[11] S. M. P. Kumar, "Silica and calcium effect on geo-technical properties of expansive soil extracted from rice husk ash and lime," in International Proceedings of Chemical Biological \& Environmenta, Singapore, Singapore, May 2012.

[12] A. S. Muntohar, "Swelling characteristics and improvement of expansive soil with rice husk ash," in Expansive Soils: Recent Advances in Characterization and Treatment, A. A. Al-Rawas and M. F. A. Goosen, Eds., Taylor \& Francis Group, Milton Park, , UK, 2006.

[13] A. K. Sabat, "Engineering properties of an expansive soil stabilized with rice husk ash and lime sludge," International Journal of Engineering \& Technology, vol. 5, no. 6, 2014.

[14] Y. Liu, Y. Su, A. Namdar, G. Zhou, Y. She, and Q. Yang, "Utilization of cementitious material from residual rice husk ash and lime in stabilization of expansive soil," Advances in Civil Engineering, vol. 2019, pp. 1-17, 2019.

[15] A. K. Sabat, "Effect of fiber on properties of rice husk ash-lime stabilised soil," in Proceedings of the Indian Geotechnical Conference, Mumbai, India, December 2010.

[16] F. H. Ali, A. Adnan, and C. K. Choy, "Use of rice husk ash to enhance lime treatment of soil," Canadian Geotechnical Journal, vol. 29, no. 5, pp. 843-852, 1992. 